\title{
Relevance of molecular changes in the ND4 gene in German Shepherd dog tumours
}

\author{
B. Ślaska ${ }^{1}$, L. Grzybowska-Szatkowska ${ }^{2}$, M. Bugno-Poniewierska ${ }^{3}$, \\ A. Gurgul ${ }^{3}$, A. Smiech ${ }^{4}$, D. Różańska ${ }^{5}$ J. Dudka ${ }^{6}$
}

${ }^{1}$ Department of Biological Bases of Animal Production,

Faculty of Animal Breeding and Biology University of Life Sciences in Lublin,

Akademicka 13, 20-950 Lublin, Poland

${ }^{2}$ Department of Oncology, Medical University of Lublin, Jaczewskiego 7, 20-090 Lublin, Poland

${ }^{3}$ Department of Genomics and Molecular Biology, National Research Institute of Animal Production, Krakowska 1, 32-083 Balice, Poland

${ }^{4}$ Department of Pathological Anatomy, Faculty of Veterinary Medicine, University of Life Sciences in Lublin, Głęboka 30, 20-612 Lublin, Poland

${ }^{5}$ Department and Clinic of Animal Surgery, Faculty of Veterinary Medicine, University of Life Sciences in Lublin, Akademicka 13, 20-950 Lublin, Poland

${ }^{6}$ Independent Medical Biology Unit, Medical University of Lublin, Jaczewskiego 8b, 20-093 Lublin, Poland

\begin{abstract}
The aim of the study was to identify polymorphisms and mutations in the mitochondrial ND4 gene and to analyse the associations between the occurrence of molecular changes in mtDNA and phenotypic traits in tumours in German Shepherd dogs. Fifty samples obtained from blood and tumour tissues of German Shepherd dogs with diagnosed tumours were analysed. DNA extraction, amplification, and sequencing of the mtDNA ND4 gene, and bioinformatics, statistical, and in silico protein coding SNP analyses were performed. ND4 mutations and/or polymorphisms were noted in eleven nucleotide positions in nearly half of the examined dogs. All the changes were substitution mutations. A majority of the changes identified were homoplasmic. In one dog with osteosarcoma, blood heteroplasmy was detected. In two positions of the ND4 gene, presence of non-synonymous mutations leading to amino acid changes in the ND4 protein was reported. Analyses carried out to determine the deleterious effect of mutations indicated an almost 97 and $62 \%$ probability that a single amino acid substitution (p.G239V and p.I401T, respectively) in the protein has a negative impact on its function. The results of statistical analyses indicate a significant association between the occurrence of mutations in three loci of the ND4 gene and the location of tumours. The mutations identified may be a result of cell adaptation to the changes in the environment occurring during carcinogenesis. The high frequency of mutations in the tumours may indicate genetic instability of mtDNA, which may also play a role in carcinogenesis.
\end{abstract}

Key words: German Shepherd, tumour, carcinogenesis, mtDNA, mutation

Correspondence to: B. Ślaska: e-mail: brygida.slaska@up.lublin.pl 


\section{Introduction}

Due to the continuous increase in their incidence and morbidity, neoplastic diseases observed both in humans and in animals have become a major problem in oncogenomics. This is particularly important in dogs, i.e. animals living close to humans, in which the number of diagnosed cancer cases is steadily increasing and is one of the major causes of fatalities. It has been observed that $50 \%$ of dogs that have lived up to 10 years die of cancers (Davis and Ostrander 2014). Tumours afflict all dog breeds, with a particularly high incidence in German Shepherd dogs (Jasik and Reichert 2015, Kaldrymidou et al. 2015, Salas et al. 2015, Treggiari et al. 2015, Surdyka and Slaska 2016a, b). This breed has been found to be susceptible to malignant vascular tumours with angiosarcoma features located in internal organs (Treggiari et al. 2015), osteosarcomas (Dobson 2013), skin cancers (Jasik and Reichert 2015, Kaldrymidou et al. 2015), and mammary cancers (Salas et al. 2015, Surdyka and Slaska 2016a,b).

Also in German Shepherd dogs, genetic abnormalities resulting in the formation of various types of tumours have been reported, for instance renal cystadenocarcinoma and nodular dermatofibrosis, which is a rare inherited cancer syndrome in this breed. Dogs develop bilateral multifocal tumours in the kidneys and multiple dense collagenous skin nodules (Moe et al. 2000). The disease gene has been mapped to a region on canine chromosome 5q12, corresponding to a gene encoding tumour-suppressor protein folliculin (Jónasdóttir et al. 2000). It has also been evidenced that abnormalities in the function of the $R B$ and TP53 genes play a role in the pathogenesis of canine osteosarcoma. One of the breeds reported to be at increased risk of developing osteosarcoma include the German Shepherd (Mendoza et al. 1997, Dobson 2013).

Currently, there is increasing evidence that mitochondrial mutations, polymorphisms, and structural functional abnormality are associated with various human tumours (Lu et al. 2009, Grzybowska-Szatkowska and Slaska, 2012a,b). However, there is little information on identification of mtDNA nucleotide changes in dog cancers (Murgia et al. 2006, Bertagnolli et al. 2009, Slaska et al. 2014, 2015, Slaska et al. 2015, Surdyka and Slaska 2016a,b). Until now, it is not clear whether the mitochondrial nucleotide changes are contributing factors in carcinogenesis or whether they simply arise as part of the secondary effects of cancer.

Mutations in mtDNA (mitochondrial DNA) associated with the proteins of the oxidative phosphorylation (OXPHOS) system may exert an effect on the mitochondrial membrane potential, which plays an important role in the apoptosis process. This process is disturbed in cancer cells, which evade the control of the cellular regulation mechanisms. In the case of the OXPHOS system cells, mutations have an effect on the activity of respiratory chain complexes (Grzybowska-Szatkowska and Slaska 2012a, Ślaska et al. 2013).

Complex I NADH dehydrogenase of the respiratory chain is involved in mitochondrial oxidative phosphorylation and is encoded in the mitochondrial genome by seven genes of mitochondrial NADH dehydrogenase. In humans, an association was found between neoplasia and mutations and polymorphisms in the sequences of respiratory chain NADH dehydrogenase (Lu et al. 2009, Grzybowska-Szatkowska and Slaska 2012a, Ślaska et al. 2013, Grzybowska-Szatkowska et al. 2014). According to Lu et al. (2009), a total of 453 mutations were reported in different types of human cancers in seven genes of complex I. Over $33 \%$ of these mutations in the ND4 gene were described by 25 research teams, including 52 missense mutations, 91 silent mutations, 2 nonsense mutations, 2 insertions, and 5 deletions in different cancer types. In the literature there is no information about mutations and polymorphism in the ND4 gene in canine cancers, including those in German Shepherd dogs, i.e. a breed characterised by genetic predisposition to carcinogenesis. Therefore, the aim of the investigations was to identify polymorphisms and mutations in the mitochondrial ND4 gene and to analyse the associations between the occurrence of molecular mtDNA changes and phenotypic traits in cancers in German Shepherd dogs.

\section{Materials and Methods}

Fifty samples obtained from blood $(n=25)$ and tumour tissues $(n=25)$ of 25 German Shepherd dogs were analysed. The specifications of the dogs and tumour types are given in Table 1. Analyses were performed on DNA isolated from post-operative tissues. Tumour tissues were collected together with blood.

Prior to DNA isolation, the histological type of the individual tissues was routinely assessed. Sections were sampled from each surgically removed tumour for histopathological analyses. The tissues were fixed in buffered formalin, embedded in paraffin blocks, and the preparations were stained with haematoxylin and eosin. Microscopic assessment of tumours was performed in accordance with the WHO histological recommendations (International Classification of $\mathrm{Tu}-$ mours of Domestic Animals). 
Table 1. Characteristics of studied cancer types in German Shepherd dogs.

\begin{tabular}{|c|c|c|c|c|c|c|}
\hline $\begin{array}{l}\text { Number } \\
\text { of dog }\end{array}$ & Tumour type/Grading system & $\begin{array}{l}\text { Origin of the } \\
\text { tumour }\end{array}$ & Location & Malignancy & Sex & $\begin{array}{l}\text { Age } \\
\text { (years) }\end{array}$ \\
\hline 2 & Epithelioma glandulae sebacei & Epithelial & $\begin{array}{l}\text { Supraorbital } \\
\text { region }\end{array}$ & $\begin{array}{l}\text { Locally } \\
\text { malignant }\end{array}$ & $\mathrm{F}$ & 7 \\
\hline 22 & Carcinoma planoepithelialae keratodes & Epithelial & Metacarpus & Malignant & M & 12 \\
\hline 38 & Carcinoma tubulo-papillare/G1 & Epithelial & Mammary gland & Malignant & $\mathrm{F}$ & 8 \\
\hline 50 & Adenocarcinoma perianale s. hepatoides & Epithelial & Penile area & Malignant & M & 13 \\
\hline 56 & Haemangiosarcoma & Mesenchymal & Spleen & Malignant & M & 10 \\
\hline 60 & Carcinoma hepatogenes & Epithelial & Liver & Malignant & M & 8 \\
\hline 62 & Carcinoma tubulo-papillare/G3 & Epithelial & Mammary gland & Malignant & $\mathrm{F}$ & 8 \\
\hline 65 & Osteosarcoma & Mesenchymal & Mammary gland & Malignant & M & 7 \\
\hline 67 & Carcinoma solidum/G2 & Epithelial & Mammary gland & Malignant & $\mathrm{F}$ & 12 \\
\hline 70 & Carcinoma tubulo-papillare/G2 & Epithelial & Mammary gland & Malignant & $\mathrm{F}$ & 12 \\
\hline 83 & Carcinoma anaplasticum/G3 & Epithelial & Mammary gland & Malignant & $\mathrm{F}$ & 13 \\
\hline 86 & Epithelioma perianale s.heptoides & Epithelial & Perianal region & $\begin{array}{l}\text { Locally } \\
\text { malignant }\end{array}$ & $\mathrm{M}$ & 10 \\
\hline 92 & Carcinoma sebaceum & Epithelial & Tail & Malignant & M & 13 \\
\hline 99 & Trichoepithelioma malignum & Epithelial & Shank & Malignant & $\mathrm{F}$ & 10 \\
\hline 104 & Sertolioma & Mesenchymal & Testicle & Malignant & M & 10 \\
\hline 106 & Carcinoma solidum/G2 & Epithelial & Mammary gland & Malignant & $\mathrm{F}$ & 9 \\
\hline 112 & Sarcoma & Mesenchymal & Head & Malignant & $\mathrm{F}$ & 10 \\
\hline 124 & Carcinoma tubulo - papillare/G1 & Epithelial & Mammary gland & Malignant & $\mathrm{F}$ & 8 \\
\hline 126 & Angiosarcoma & Mesenchymal & Spleen & Malignant & $\mathrm{F}$ & 9 \\
\hline 130 & Carcinoma complexus/G1 & Epithelial & Mammary gland & Malignant & M & 12 \\
\hline 136 & Haemangiopericytoma & Mesenchymal & Finger & $\begin{array}{l}\text { Locally } \\
\text { malignant }\end{array}$ & $\mathrm{F}$ & 7 \\
\hline 152 & Adenocarcinoma & Epithelial & Kidney & Malignant & M & 5 \\
\hline 177 & Angiosarcoma & Mesenchymal & Spleen & Malignant & M & 8 \\
\hline 196 & Haemangiopericytoma & Mesenchymal & Scrotum & $\begin{array}{l}\text { Locally } \\
\text { malignant }\end{array}$ & M & 11 \\
\hline 197 & Angiosarcoma & Mesenchymal & Liver & Malignant & M & 11 \\
\hline
\end{tabular}

DNA was extracted from tumour tissues and their matched blood samples using the DNeasy Blood \& Tissue Kit (Qiagen). DNA samples were assessed quantitatively and qualitatively by electrophoretic separation in agarose gel and spectrophotometrically by measurements of sample absorbance in a BioPhotometer (Eppendorf, Germany) spectrophotometer.

The isolated DNA was used to amplify the mitochondrial gene ND4 (NADH dehydrogenase subunit 4) (782 bp (base pair) fragment). The PCR primers (ND4F: 5' ATCCAGCCTCTGCCAAACTC 3' (Primer position (bp): 10747-10766) and ND4R: 5' GGCAGTAGGTGCAAGGTCAT 3' (Primer position (bp): 11528-11509) were designed according to the canine reference sequence (Canis lupus familiaris) deposited in the GenBank (NC_002008.4, Kim et al. 1998). Optimal conditions and the reaction mixture for amplification were determined. The annealing temperature for the analysed gene was $58.5^{\circ} \mathrm{C}$.

Amplification of two fragments of the ND4 gene of mitochondrial DNA was performed with the PCR technique in a Labocycler Thermal Cycler (Sensoquest Biomedical). Amplification products were visualised on 2\% agarose gel. Amplicons were sequenced using a BigDye Terminator Cycle Sequencing kit (Applied Biosystem, USA) in a 9700 GeneAmp PCR system (Applied Biosystem, USA). The samples were subsequently purified on CentriSep columns according to the manufacturer's protocol or precipitated with ethanol and sodium acetate according to the protocol of the BigDye kit manufacturer. Extension products were separated on an ABI 377 automated sequencer (Applied Biosystem, USA).

Nucleotide sequences were analysed using bioinformatics programs to determine the presence or absence of mutations and polymorphisms in the analysed locus and tissues (DNA Baser Sequence Assembler v 3.2 (2012); MEGA v 6.0 (Tamura et al. 2013)). Sequences of the analysed genes were compared with the canine reference sequence. The polymorphisms involved changes that occur in blood and tumour cells in the same dog. Mutation is a change characteristic only for tumour cells and not occurring in dog's blood.

Statistical analyses were carried out taking into account the malignancy grade $(\mathrm{G} 1, \mathrm{G} 2, \mathrm{G} 3)$, malignancy (malignant, locally malignant), origin of the tumour (epithelial, mesenchymal), location ((1) mam- 
Table 2. Polymorphisms in mitochondrial ND4 gene in blood and tumour tissue in German Shepherd dogs.

\begin{tabular}{|c|c|c|c|c|c|c|}
\hline $\begin{array}{l}\text { Number } \\
\text { of dog }\end{array}$ & Tumour type & $\begin{array}{l}\text { Reference } \\
\text { sequence }\end{array}$ & $\begin{array}{l}\text { Sequences in } \\
\text { dog's blood }\end{array}$ & $\begin{array}{c}\text { Sequences } \\
\text { in tumour cells }\end{array}$ & $\begin{array}{l}\text { Amino acid } \\
\text { change }\end{array}$ & $\begin{array}{l}\text { Position of } \\
\text { changed } \\
\text { ucleotide } \\
\text { in codon }\end{array}$ \\
\hline \multirow{4}{*}{50} & \multirow{4}{*}{$\begin{array}{l}\text { Adenocarcinoma perianale } \\
\text { s. hepatoides }\end{array}$} & m.10917G & m.G10917A & m.G10917A & G239G & $\mathrm{GGG} \rightarrow \mathrm{GGA}$ \\
\hline & & m.11176C & m.C11176T & m.C11176T & p.L326L & $\mathrm{CTA} \rightarrow \mathrm{TTA}$ \\
\hline & & m.11250T & m.T11250C & m.T11250C & p.T350T & $\mathrm{ACT} \rightarrow \mathrm{ACC}$ \\
\hline & & $\mathrm{m} .11402 \mathrm{~T}$ & m.T11402C & m.T11402C & p.I401T & $\mathrm{ATC} \rightarrow \mathrm{ACC}$ \\
\hline 67 & Carcinoma solidum & m.10992G & m.G10992A & m.G10992A & p.L264L & $\mathrm{TTG} \rightarrow \mathrm{TTA}$ \\
\hline 92 & Carcinoma sebaceum & m.10992G & m.G10992A & m.G10992A & p.L264L & $\mathrm{TTG} \rightarrow \mathrm{TTA}$ \\
\hline 106 & Carcinoma solidum & m.10992G & m.G10992A & m.G10992A & p.L264L & $\mathrm{TTG} \rightarrow \mathrm{TTA}$ \\
\hline 112 & Sarcoma & m.10992G & m.G10992A & m.G10992A & p.L264L & $\mathrm{TTG} \rightarrow \mathrm{TTA}$ \\
\hline \multirow{4}{*}{126} & \multirow{4}{*}{ Angiosarcoma } & m.10917G & m.G10917A & m.G10917A & p.G239G & $\mathrm{GGG} \rightarrow \mathrm{GGA}$ \\
\hline & & m.11176C & m.C11176T & m.C11176T & p.L326L & $\mathrm{CTA} \rightarrow \mathrm{TTA}$ \\
\hline & & m.11250T & m.T11250C & m.T11250C & p.T350T & $\mathrm{ACT} \rightarrow \mathrm{ACC}$ \\
\hline & & $\mathrm{m} .11402 \mathrm{~T}$ & m.T11402C & m.T11402C & p.I401T & $\mathrm{ATC} \rightarrow \mathrm{ACC}$ \\
\hline 130 & Carcinoma complexus & m.10992G & m.G10992A & m.G10992A & p.L264L & $\mathrm{TTG} \rightarrow \mathrm{TTA}$ \\
\hline 177 & Angiosarcoma & m.10992G & m.G10992A & m.G10992A & p.L264L & $\mathrm{TTG} \rightarrow \mathrm{TTA}$ \\
\hline
\end{tabular}

Table 3. Differences between blood and tumor tissue in ND4 gene in German Shepherd dogs.

\begin{tabular}{|c|c|c|c|c|c|}
\hline $\begin{array}{l}\text { Number } \\
\text { of dog }\end{array}$ & Tumour type & $\begin{array}{l}\text { Sequences in } \\
\text { dog's blood }\end{array}$ & $\begin{array}{l}\text { Sequences in } \\
\text { cancer cells }\end{array}$ & $\begin{array}{c}\text { Amino acid } \\
\text { change }\end{array}$ & $\begin{array}{l}\text { Position of } \\
\text { changed } \\
\text { nucleotide } \\
\text { in codon }\end{array}$ \\
\hline 62 & Carcinoma tubulo-papillare & m.10992G & m.10992A & p.L264L & $\mathrm{TTG} \rightarrow \mathrm{TTA}$ \\
\hline 65 & Osteosarcoma & m. A11442A/T & m.11442A & p.T414T & $\mathrm{ACA} \rightarrow \mathrm{ACT}$ \\
\hline \multirow[t]{4}{*}{126} & Angiosarcoma & m.10916G & m.10916T & p.G239V & $\mathrm{GGG} \rightarrow \mathrm{GTG}$ \\
\hline & & m.10863G & m.10863A & p.V221V & $\mathrm{GTA} \rightarrow \mathrm{GTG}$ \\
\hline & & m.10917A & m.10917G & p.G239G & $\mathrm{GGG} \rightarrow \mathrm{GGA}$ \\
\hline & & m.11250C & m.11250T & p.T350T & $\mathrm{ACT} \rightarrow \mathrm{ACC}$ \\
\hline \multirow[t]{7}{*}{196} & Haemangiopericytoma & $\mathrm{m} .11322 \mathrm{C}$ & m.11322T & p.N374N & $\mathrm{AAT} \rightarrow \mathrm{AAC}$ \\
\hline & & m.11400C & m.11400T & p.I400I & $\mathrm{AAT} \rightarrow \mathrm{ATC}$ \\
\hline & & m.11402C & m.11402T & p.I401T & $\mathrm{ATC} \rightarrow \mathrm{ACC}$ \\
\hline & & m.11431C & $\mathrm{m} .11431 \mathrm{~T}$ & p.L411L & $\mathrm{TTA} \rightarrow \mathrm{CTA}$ \\
\hline & & m.10863A & m.10863G & p.V221V & $\mathrm{GTA} \rightarrow \mathrm{GTG}$ \\
\hline & & m.10917G & m.10917A & p.G239G & $\mathrm{GGG} \rightarrow \mathrm{GGA}$ \\
\hline & & $\mathrm{m} .11250 \mathrm{~T}$ & m.11250C & p.T350T & $\mathrm{ACT} \rightarrow \mathrm{ACC}$ \\
\hline \multirow[t]{4}{*}{197} & Angiosarcoma & m.11322T & m.11322C & p.N374N & $\mathrm{AAT} \rightarrow \mathrm{AAC}$ \\
\hline & & m.11400T & m.11400C & p.I400I & $\mathrm{AAT} \rightarrow \mathrm{ATC}$ \\
\hline & & m.11402T & m.11402C & p.I401T & $\mathrm{ATC} \rightarrow \mathrm{ACC}$ \\
\hline & & m.11431T & m.11431C & p.L411L & $\mathrm{TTA} \rightarrow \mathrm{CTA}$ \\
\hline
\end{tabular}

mary gland, (2) limbs, (3) internal organs, (4) genital area, (5) head), sex, and age (mature adult - from 5 to 9 years old and geriatric - from 10 to 15 years old). The probability of occurrence of polymorphism and mutation in each locus depending on the above-mentioned factors was estimated using the method of least-squares means (lsm \pm se (standard error). The association between the data was analysed using the SAS 9.4 procedure PROC GLM (SAS Institute, Cary, NC, USA). Associations with $\mathrm{p} \leq 0.05$ were considered significant.

The probability of deleterious mutations, i.e. the functional effect of the non-synonymous (amino acid-changing) protein coding SNP, was determined using the Panther Classification System (http://www.pantherdb.org/), which estimates the value of substitution position-specific evolutionary conservation (subPSEC) and the probability of a deleterious effect on protein function $\left(\mathrm{P}_{\text {deleterious, }}\right.$ Probability of Functional Impairment) on the basis of the alignment of evolutionarily determined proteins. PANTHER subPSEC scores are continuous values from 0 (neutral) to about -10 (most likely to be deleterious). -3 is the previously identified cutoff point for functional significance. A cutoff of -3 corresponds to a $50 \%$ probability that a SNP is deleterious. From this, the probability that a given variant will cause a deleterious effect on protein function is estimated 
by $\mathrm{P}_{\text {deleterious, }}$, such that a subPSEC score of -3 corresponds to a $P_{\text {deleterious }}$ of 0.5 . The incidence of amino acid substitution in each position of a protein sequence was assessed using Position Specific Scoring Matrix (PSSM). PSSM scores are generally shown as positive or negative integers. Positive scores indicate that a given amino acid substitution occurs more frequently in an alignment than expected by chance, while negative scores indicate that a substitution occurs less frequently than expected. Large positive scores often indicate critical functional residues, which may signify active site residues or residues required for other intermolecular interactions (http://www.ncbi.nlm.nih.gov/Class/Structure/pssm/pss m_viewer.cgi). To determine the effect of an amino acid change on the transmembrane structure, the TMHMM Server program (Prediction of transmembrane helices in proteins) (http://www.cbs.dtu.dk/services/TMHMM/) was used.

The study was approved by the II Local Ethical Commission for Animal Experiments in Lublin, Poland (Resolution number 6/2013).

\section{Results}

The analysis of the ND4 gene sequence of German Shepherds with malignant and locally malignant tumours has shown a relatively high genetic variability. Tables 2 and 3 present the results of analysis of ND4 gene sequences in tissues sampled from dogs diagnosed with tumours. In this study, 25 German Shepherd dogs had a total number of five polymorphisms and ten mutations (Tables 2 and 3 ).

Mutations and/or polymorphisms in ND4 were noted in eleven nucleotide positions, not described in the literature, in nearly half of the examined dogs with diagnosed tumours (Tables 2 and 3). The highest frequency, i.e. in $28 \%$ of the German Shepherd dogs, was found for substitution in position m.G10992A in mtDNA. The greatest number - seven mutations in each - was detected in two dogs with haemangiopericytoma (sample 196) and angiosarcoma (sample 197). All the detected changes were substitution mutations and no ins/del (insertion/deletion) type was noted. A majority of the changes identified in the analysed material were homoplasmic. In one individual with osteosarcoma, heteroplasmy in blood was noted in position m. A11442A/T (Table 3, Fig. 1).

In most cases, the polymorphisms and mutations did not induce a change in the amino acid sequence of the protein; they were silent nucleotide substitutions (Tables 2, 3). In two positions of the ND4 gene, the presence of a non-synonymous nucleotide change was observed: in position m.11402 in four tumours (Fig. 1) leading to amino acid changes (p.I401T) and in position m.10916 in the angiosarcoma case (sample 126) - a mutation leading to an amino acid change in the ND4 protein (p.G239V) (Tables 2, 3).

The analyses focused on determination of the deleterious effect of the mutations and revealed that, in the case of the conversion of glycine amino acid (Gly) to valine (Val) (p.G239V) as well as isoleucine (Ile) to threonine (Thr) (p.I401T), the subPSEC value was -3.7 and -1.2 , respectively, whereas the value of $P_{\text {deleterious }}$ in the case of the p.G239V substitution was close to 0.7 (Table 4).

Both amino acid changes p.G239V and p.I401T seem to have an impact on the functioning of the ND4 protein, taking into account the values of subPSEC (-6.4 and -3.5 , respectively) and $\mathrm{P}_{\text {deleterious }}(0.97$ and 0.62 , respectively) (Table 4$)$. In the ND4 protein in position p.239, the amino acid - Gly is nonessential, in contrast to Val (essential), and must be included in the human diet. Gly and Val are aliphatic, nonpolar amino acids, and both contain a methylene group. Mutation m.G10916T converts the highly conserved glycine (PSSM score $=7$ ) to valine (PSSM score $=-5$ ). In ND4 protein in position p.401, the amino acid Ile is nonpolar and hydrophobic and contains a methylene group, in contrast to Thr, which in this position is polar and hydrophilic and contains a hydroxyl group. Both of them are aliphatic and essential amino acids. Mutation m.T11250C converts moderately conserved isoleucine (PSSM score $=2$ ) to poorly conserved threonine (PSSM score $=1)$.

The results of the statistical analyses indicate a significant association between the occurrence of mutations in three loci (m.10917, m.11250, m.11402) and the location of tumours. Significant differences in the probability of their occurrence were noted between group 1 (mammary tumour) and 3 (tumours of internal organs $)(p=0.0431)$ and between group 1 (mammary tumour) and 4 (tumours of the genital area) $(p=0.0225)$. The probability of mutations in the tumours of internal organs and genital area was statistically significantly higher than the probability of their occurrence in mammary gland cancer. In the other analysed cases, there was no significant correlation between the probability of occurrence of any mutation and the malignancy grade, malignancy, origin of the tumour, sex, and age.

\section{Discussion}

Neoplastic transformations in German shepherd dogs may appear at any age; however, it is older animals at the age of 10 that are most frequently afflicted by the disease (Peterson et al. 2000). In this study, no 

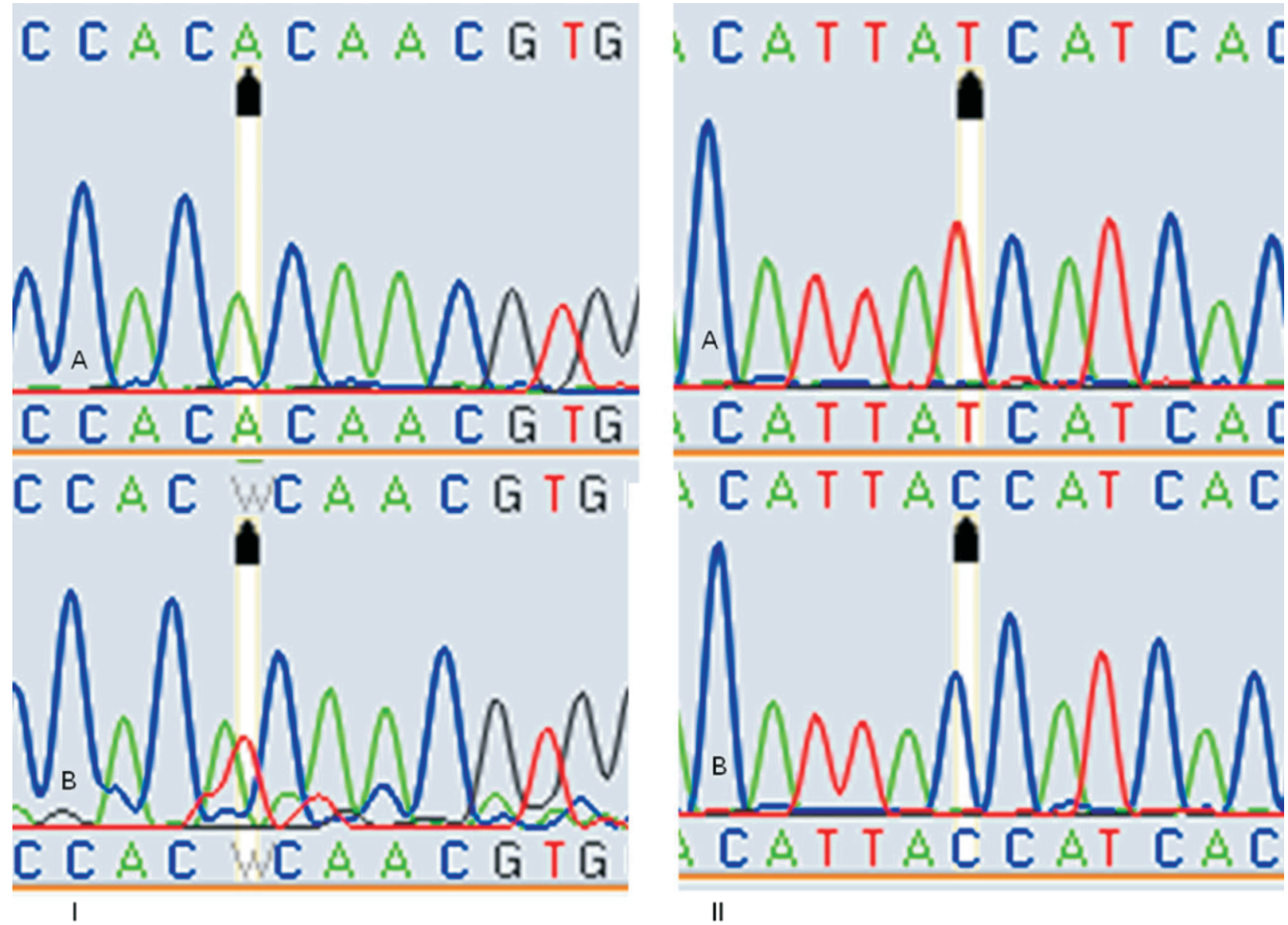

Fig. 1. Blood heteroplasmy (I) m. A11442A/T in osteosarcoma and non-synonymous (amino acid-changing) protein coding SNP m.T11402C (II) in angiosarcoma (A - tumour tissue, B - blood).

Table 4. Probability of a functional effect on non-synonymous protein-coding SNP.

\begin{tabular}{ccccccc}
\hline subPSEC & $\mathrm{P}_{\text {deleterious }}$ & substitution & MSA position & $\mathrm{P}_{\mathrm{wt}}$ & $\mathrm{P}_{\text {substituted }}$ & NIC \\
\hline-6.36272 & 0.96652 & p.G239V & 268 & 0.76172 & 0.00625 & 9.196 \\
-3.50383 & 0.62336 & p.I401T & 450 & 0.1382 & 0.02881 & 9.223 \\
\hline
\end{tabular}

dogs younger than five years of age presented with cancer, and the average age at tumour diagnosis was 9 years and 9 months (Table 1 ). Some breeds of dogs exhibit increased predilection for development of certain types of cancer (Dobson 2013). As reported by Salas et al. (2015), besides poodles and spaniels, German Shepherd females are characterised by an increased risk of occurrence of mammary tumours. Also according to Surdyka and Slaska (2016a, b), German Shepherd-type females constitute more than $30 \%$ of various breeds of dogs with diagnosed mammary tumours. This is confirmed by the incidence of mammary tumours in the examined group of German Shepherd dogs. These cancers exhibited the highest frequency (0.36), compared with the other tumour types (Table 1$)$.
The available literature does not provide reports of the association between gene ND4 mutations and canine tumours. This study has shown for the first time the occurrence of polymorphisms and mutations in eleven positions of the gene associated with carcinogenesis in German Shepherd dogs. It is known currently that carcinogenesis has a homologous background in the case of many nuclear genes in humans and dogs (Ślaska et al. 2013). Numerous reports also indicate a close relationship between mtDNA mutations in humans and neoplastic transformation, including genes encoding mitochondrial NADH-dehydrogenase (Brandon et al. 2006, Lu et al. 2009, Grzybowska-Szatkowska and Slaska 2012a, Grzybowska-Szatkowska and Slaska 2014). In contrast, nucleotide changes in mtDNA associated with 
carcinogenesis in dogs have been described in only a few papers (Murgia et al. 2006, Bertagnolli et al. 2009, Slaska et al. 2014, 2015, Ślaska et al. 2015, Surdyka and Slaska 2016a,b), which however did not present mutations in the ND4 gene or a homogeneous group of one breed dogs - the German Shepherd. Therefore, the results presented in this paper have a pioneer character, as they demonstrate an association between somatic mutations in the ND4 gene sequence and malignant and locally malignant tumours in German Shepherd dogs.

The detection of only substitution mutations (Tables 2,3) is in agreement with literature data on human and canine cancers. These are the most frequent nucleotide changes in mtDNA in the case of tumours diagnosed in both species (Brandon et al. 2006, Lu et al. 2009, Grzybowska-Szatkowska and Slaska, 2012a, b, Slaska et al. 2014, 2015, Ślaska et al. 2015, Surdyka and Slaska 2016a,b). The subPSEC and Pdeleterious values obtained in the case of the substitutions p.G239V and p.I401T in NADH dehydrogenase subunit 4 (Table 4) indicated a nearly $97 \%$ and $62 \%$ probability, respectively, of a negative effect of the change in a single amino acid in the protein on its function. However, it did not cause changes in the transmembrane structures. Glycine in position p.239 in the protein is a fully conserved amino acid favoured in conserved domains (PSSM score $=7$ ). The negative score (-5) for valine also indicates that this substitution is not favoured in the protein function and may be deleterious. Isoleucine in position p.401 in the protein is a moderately conserved amino acid, whereas threonine is a poorly conserved and less favoured amino acid.

The changes in the amino acid in both position 239 and position 401 involve the transmembrane helix. In humans, non-synonymous mutations in ND4L and ND4 have been detected in Leber hereditary optic neuropathy (LHON) (Abu-Amero and Bosley 2006) and changes in ND4 have been shown in oncocytic transformation (Porcelli et al. 2010). Additionally, mutations in the respiratory chain complex I including subunit ND4 in human thyroid carcinomas causing respiratory deficit (Abu-Amero et al. 2005) and in breast cancer have been described (Parrella $e t$ al. 2001). In animals, particularly in dogs with cancers, no mutations in ND4 have been detected so far.

The other polymorphisms and mutations (Tables 3 and 4) were synonymous, which potentially implies absence of an impact on the protein. Nevertheless, this view is disputed in the literature. Despite the absence of a change in a nascent polypeptide chain, mutations may disturb splicing and interfere in miRNA binding (Parmley and Hurst 2007), cause disturbances in protein synthesis related to changes in mRNA sta- bility and changes in its secondary structure (Nackley et al. 2006), and modify the structure and activity of proteins (Kimchi-Sarfaty et al. 2007) by mediating the induction of translational pausing. These examples demonstrate that a synonymous mutation does not have to be neutral. The presence of polymorphisms in mtDNA may result in a slight increase in the level of free radicals. It cannot be excluded that polymorphisms may constitute additional changes that favour the occurrence of a selective advantage of mutant mtDNA (Bianchi et al. 2001).

A majority of the mutations detected in the tumours in the German Shepherd dogs were homoplasmic, which is in agreement with the data on changes in mtDNA in human and canine tumours reported in the literature (Brandon et al. 2006, Lu et al. 2009, Grzybowska-Szatkowska and Slaska 2012a,b, 2014, Slaska et al. 2014, 2015, Ślaska et al. 2015, Surdyka and Slaska 2016a,b). Currently, only a few heteroplasmy changes associated with tumours in different dog breeds have been described. However, their small number is associated with the scarcity of available literature data on this issue. Blood and cancer heteroplasmy was diagnosed in the D-loop region for epithelioma glandulae sebacei tissue (German Shepherd), carcinoma planoepithelialae keratodes and "Comedo" carcinoma in crossbreed dogs (Slaska et al. 2014) as well as in tumour tissue of carcinoma hidradenoides in German Shepherds (Ślaska et al. 2014). Heteroplasmic changes were also found in ND1 and $C Y T B$ in epithelioma glandulae sebacei only in cancer tissue (German Shepherd) as well as in CYTB in lymphoma centroblasticum in cancer tissue and blood (Bernese Mountain Dog) (Slaska et al. 2015). Also length heteroplasmy was detected in dogs with mammary tumours, which may imply that this is a hotspot mutation (Surdyka and Slaska 2016a). In this study, heteroplasmy was detected in the blood of one individual with osteosarcoma in position m.A1242A/T mtDNA (Table 3). Heteroplasmy in the blood, and not in tumour tissue, was detected in mt-tRNA for threonine (TRNT gene) in female breast cancer by Grzybowska-Szatkowska and Slaska (2012b). It was concluded during analyses of cancer tissues and blood taken from patients with breast cancer that heteroplasmy emerged due to contamination with circulating neoplastic cells.

The presence of heteroplasmy only in blood (Table 3) may be a consequence of contamination with circulating cancer cells or recombination of maternal and paternal mtDNA as well as occurrence of two mtDNA types in normal tissues (Grzybowska-Szatkowska and Slaska 2012a,b, Slaska et al. 2014, Surdyka and Slaska 2016a,b). In turn, the presence of one mtDNA type in tumour tissue may be a result of 
intramitochondrial selection leading to dominance of one type of mtDNA in the mitochondrion, i.e. the so-called functional advantage. During division, the cell is targeted at the advantage and presence of one mtDNA type, i.e. homoplasmy (replicative segregation). The period required for the replicative segregation would correspond with the neoplastic transformation phase. Homoplasmy is found to emerge through random segregation of mitochondria during cell division. In subsequent generations of progeny cells, heteroplasmy can persist or homoplasmy may emerge through genetic drift. Genetic drift leads to elimination or stabilisation of rare mtDNA variants (Grzybowska-Szatkowska and Slaska 2012a, 2014). This seems to be the case in carcinogenesis.

So far, there have been only a few reports on the association between phenotypic traits and carcinogenesis in dogs. This issue was addressed in one study, in which no association between the age, breed, sex, type of tumour, and detected polymorphic variants was observed (Ślaska et al. 2014), as well as in the second study, in which the tumour malignancy grade did not exert an influence on the presence of polymorphisms, but a statistically significant association was shown between the dogs' size and the occurrence of polymorphisms in four mtDNA positions (Surdyka and Slaska 2016a). In the present study, a significant association between mutations in the three loci (m.10917, m.11250, m.11402) and the location of tumours was found. The probability of mutations in dogs with tumours of internal and genital organs was found to be significantly higher than that in dogs with mammary cancer. The results obtained cannot be explained by the origin of the tumours, since no significant differences in the probability of mutations between tumours of different origin were noted in the present study, and this hypothesis is consistent with literature data. On the basis of molecular analyses of the D-loop of mtDNA, Bertagnolli et al. (2009) have found that the epithelial and mesenchymal elements of canine tumours have a common origin.

The literature presents debates over two theories combining the mutagenesis and carcinogenesis processes. It has been postulated that the presence of abnormalities in the genetic material, or mitochondrial mutations may not precede the development of tumours but are their consequence. These mutations may result from adaptation of the cell to the changing environment during carcinogenesis, as is the case in the course of animal evolution (Slaska and Grzybowska-Szatkowska 2011, Grzybowska-Szatkowska et al. 2014). The presence of abnormalities in the genetic material promotes carcinogenesis; hence, any mutations, including those in mtDNA, increase the risk of neoplastic transformation. Mutations pres- ent only in tumour tissue may have emerged during the neoplastic transformation process. The frequent occurrence of mtDNA mutations in tumours may imply genetic instability of mtDNA, which may play a role in carcinogenesis.

\section{References}

Abu-Amero KK, Bosley TM (2006) Mitochondrial abnormalities in patients with LHON-like optic neuropathies. Invest Ophthalmol Vis Sci 47: 4211-4220.

Abu-Amero KK, Alzahrani AS, Zou M, Shi Y (2005) High frequency of somatic mitochondrial DNA mutations in human thyroid carcinomas and complex I respiratory defect in thyroid cancer cell lines. Oncogene 24: 1455-1460.

Bertagnolli AC, Sores P, van Asch B, Amorim A, Cirnes L, Maximo V, Cassali GD (2009) An assessment of the clonality of the components of canine mixed mammary tumors by mitochondrial DNA analysis. Vet $\mathrm{J}$ 182: 269-274.

Bianchi NO, Bianchi MS, Richard SM (2001) Mitochondrial genome instability in human cancers. Mutat Res 488: 9-23.

Brandon M, Baldi P, Wallace DC (2006) Mitochondrial mutations in cancer. Oncogene 25: 4647-4662.

Davis BW, Ostrander EA (2014) Domestic dogs and cancer research: a breed-based genomics approach. ILAR J 55: 59-68.

Dobson JM (2013) Breed-Predispositions to Cancer in Pedigree Dogs. ISRN Vet Sci 2013: 941275.

Grzybowska-Szatkowska L, Slaska B (2012a) Mitochondrial DNA and carcinogenesis (review). Mol Med Rep 6: 923-930.

Grzybowska-Szatkowska L, Slaska B (2012b) Polymorphisms in genes encoding mt-tRNA in female breast cancer in Poland. Mitochondrial DNA 23: 106-111.

Grzybowska-Szatkowska L, Slaska B (2014) Mitochondria $\mathrm{NADH}$ dehydrogenase polymorphisms are associated with breast cancer in Poland. J Appl Genet 55: 173-181.

Grzybowska-Szatkowska L, Slaska B, Rzymowska J, Brzozowska A, Floriańczyk B (2014) Novel mitochondrial mutations in the ATP6 and ATP8 genes in patients with breast cancer. Mol Med Rep 10: 1772-1778.

Jasik A, Reichert M (2009) Epidemiological analysis of canine skin tumors. Med Weter 65: 848-853.

Jónasdóttir TJ, Mellersh CS, Moe, Heggeb $\varnothing$ R, Gamlem H, Ostrander EA, Lingaas F (2000) Genetic mapping of a naturally occurring hereditary renal cancer syndrome in dogs. Proc Natl Acad Sci USA 97: 4132-4137.

Kaldrymidou H, Leontides L, Koutinas AF, Saridomichelakis MN, Karayannopoulou M (2002) Prevalence, Distribution and Factors Associated with the Presence and the Potential for Malignancy of Cutaneous Neoplasms in 174 Dogs Admitted to a Clinic in Northern Greece. J Vet Med A 49: 87-91.

Kim KS, Lee SE, Jeong HW, Ha JH (1998) The complete nucleotide sequence of the domestic dog (Canis familiaris) mitochondrial genome. Mol Phylogenet Evol 10: 210-220.

Kimchi-Sarfaty C, Oh JM, Kim IW, Sauna ZE, CalcagnoAM, AmbudkarSV, Gottesman MM (2007) A „silent” polymorphism in the MDR1 gene changes substrate specificity. Science 315: 525-528. 
Lu J, Sharma LK, Bai Y (2009) Implications of mitochondrial DNA mutations and mitochondrial dysfunction in tumorigenesis. Cell Res 19: 802-815.

Mendoza S, Konishi T, Dernell WS, Withrow SJ, Miller CW (1997) Status of the $\mathrm{p} 53, \mathrm{Rb}$ and MDM 2 genes in canine osteosarcoma. Anticancer Res 18: 4449-4453.

Moe L, Gamlem H, Jonasdottir TJ, Lingaas F (2000) Renal Microcystic Tubular Lesions in Two 1Year-old Dogs-An Early Sign of Hereditary Renal Cystadenocarcinoma? J Comp Pathol 123: 218-221.

Murgia C, Pritchard JK, Kim SY, Fassati A, Weiss RA (2006) Clonal Origin and Evolution of a Transmissible Cancer. Cell 126: 477-487.

Nackley AG, Shabalina SA, Tchivileva IE, Satterfield K, Korchynskyi O, Makarov SS, Maixner W, Diatchenko L (2006) Human catechol-O-methyltransferase haplotypes modulate protein expression by altering mRNA secondary structure. Science 314: 1930-1933.

Parmley JL, Hurst LD (2007) How do synonymous mutations affect fitness? Bioessays 29: 515-519.

Parrella P, Xiao Y, Fliss M, Sanchez-Cespedes M, Mazzarelli P, Rinaldi M, Nicol T, Gabrielson E, Cuomo C, Cohen D, Pandit S, Spencer M, Rabitti C, Fazio VM, Sidransky D (2001) Detection of mitochondrial DNA mutations in primary breast cancer and fine-needle aspirates. Cancer Res 61: 7623-7626.

Peterson MR, Frommelt RA, Dunn DG (2000) A Study of the Lifetime Occurrence of Neoplasia and Breed Differences in a Cohort of German Shepherd Dogs and Belgian Malinois Military Working Dogs that Died in 1992. J Vet Intern Med 14: 140-145.

Porcelli AM, Ghelli A, Ceccarelli, Lang M, Cenacchi G, Capristo M, Pennisi LF, Morra I, Ciccarelli E, Melcarne A, Bartoletti-Stella A, Salfi N, Tallini G, Martinuzzi A, Carelli V, Attimonelli M, Rugolo M, Romeo G, Gasparre G (2010) The genetic and metabolic signature of oncocytic transformation implicates HIF1alpha destabilization. Hum Mol Genet 19: 1019-1032.
Salas Y, Márquez A, Diaz D, Romero L (2015) Epidemiological Study of Mammary Tumors in Female Dogs Diagnosed during the Period 2002-2012: A Growing Animal Health Problem. PLoS One 10: e0127381.

Slaska B, Grzybowska-Szatkowska L (2011) Analysis of the mitochondrial haplogroups of farm and wild-living raccoon dogs in Poland. Mitochondrial DNA 22: 105-110.

Slaska B, Grzybowska-Szatkowska L, Nisztuk S, Surdyka M, Rozanska D (2015) Mitochondrial DNA polymorphism in genes encoding ND1, COI and CYTB in canine malignant cancers. Mitochondrial DNA 26: 452-458.

Slaska B, Grzybowska-Szatkowska L, Surdyka M, Nisztuk, S, Rozanska D, Rozanski P, Smiech A, Orzelski M (2014) Mitochondrial D-loop mutations and polymorphisms are connected with canine malignant cancers. Mitochondrial DNA 25: 238-243.

Surdyka M, Slaska B (2016a) Defect of the mitochondrial DNA hypervariable region as a risk factor for canine mammary tumour. Vet Comp Oncol DOI:10.1111/vco.12224.

Surdyka M, Slaska B (2016b). Defect in ND2, COX2, ATP6, and $\mathrm{COX} 3$ mitochondrial genes as a risk factor for canine mammary tumour. Vet Comp Oncol DOI: 10.1111/vco. 12247

Ślaska B, Grzybowska-Szatkowska L, Bugno-Poniewierska M, Surdyka M, Śmiech A (2013) Nuclear and mitochondrial DNA mutation in human and canine tumors. Med Weter 69: 195-202.

Ślaska B, Surdyka M, Brodzki A, Nisztuk S, Gurgul A Bugno-Poniewierska M, Śmiech A, Różańska D, Orzelski M (2014) Mitochondrial D-loop mutations can be detected in sporadic malignant tumours in dogs. Bull Vet Inst Pulawy 58: 631-637.

Tamura K, Stecher G, Peterson D, Filipski A, Kumar $S$ (2013) MEGA6: molecular evolutionary genetics analysis version 6.0. Mol Biol Evol 30: 2725-2729.

Treggiari E, Pedro B, Dukes-McEwan J, Gelzer AR, Blackwood L (2015) A descriptive review of cardiac tumours in dogs and cats. Vet Comp Oncol DOI: 10.1111/vco.12167. 